\title{
Diagnostic accuracy of mean arterial pressure in second trimester for prediction of preeclampsia in females.
}

\footnotetext{
1. FCPS (Obs \& Gynae) Registrar Faisalabad Institute of Cardiology, Faisalabad.

2. FCPS (Card.)

Resident Interventional Cardiology Faisalabad Institute of Cardiology, Faisalabad.

3. FCPS (Obs \& Gynae) Consultant Gynecologist Health Bridge Hospital \& National Hospital Lahore.

4. MCPS (Med.), FCPS (Card.) Associate Professor Cardiology Faisalabad Institute of Cardiology, Faisalabad.

5. FCPS (Card.) Assistant Professor Cardiology Faisalabad Institute of Cardiology, Faisalabad
}

Correspondence Address:

Dr. Naeem Hameed

Senior Registra

Faisalabad Institute of Cardiology, Faisalabad.

dr_naeem80@hotmail.com

Article received on:

15/06/2021

Accepted for publication: 13/09/2021

\section{INTRODUCTION}

Preeclampsia $(\mathrm{PE})$ is high blood pressure $(\mathrm{BP})$ that occurs after 20 weeks of pregnancy and is accompanied by proteinuria. ${ }^{1}$ It is a leading cause of perinatal and maternal morbidity and mortality, affecting more than $2 \%$ of pregnancies. ${ }^{2}$ Preeclampsia was shown to be 26 percent more likely in nulliparous patients and 17 percent more likely in multiparous patients in one study. ${ }^{3}$ The most prevalent medical condition that occurs during pregnancy is hypertension. In the United States, hypertensive disorders are the leading cause of maternal death during pregnancy. ${ }^{4}$

Incomplete placentation is the most common cause of PE. PE is categorized into two types: early onset $\mathrm{PE}$, which requires delivery before 34 weeks of pregnancy, and late onset PE, which requires delivery at or beyond 34 weeks of pregnancy. Early onset has been linked to a higher risk of negative mother and foetal outcomes. For

\begin{abstract}
Sidra Mushtaq', Naeem Hameed ${ }^{2}$, Rabika Bint Khamis Butt ${ }^{3}$, Shahid Abbas ${ }^{4}$, Ali Sajjad ${ }^{5}$ study. Setting: Department of Obstetrics \& Gynecology Unit III, Allied hospital, Faisalabad. Period: October 2016 to September 2017. Material \& Methods: Total 386 patients were nrolled after obtaining informed consent. Booked females of age $18-40$ years, parity $<5$ ( having oligohydramnios $(\mathrm{AFI}<5 \mathrm{~cm}$ ) or polyhydramnios (AFI $>21 \mathrm{~cm}$ ) on USG, females having abnormal placental implantation or placental abruption (on USG) were excluded. The mean age of the patients was $28.59 \pm 6.93$ years. The MAP of the patients was $94.88 \pm 14.68 \mathrm{mmHg}$. Results. The sensitivity, specificity and diagnostic accuracy of MAP was $92.89 \%, 89.12 \%$ and pressure in second trimester is very effective and useful screening method for prediction of preeclampsia with high values of sensitivity, specificity and diagnostic accuracy.
\end{abstract}

Key words: Mean Arterial Pressure, Preeclampsia, Trimester.

Article Citation: Mushtaq S, Hameed N, Butt RBK, Abbas S, Sajjad A. Diagnostic accuracy of mean arterial pressure in second trimester for prediction of preeclampsia in females. Professional Med J 2021; 28(12):1758-1762.

https://doi.org/10.29309/TPMJ/2021.28.12.6649

a better outcome, early detection of PE in highrisk pregnancies, as well as preventive medical treatment for disease progression and foetal and maternal surveillance, is required. ${ }^{5}$

Apart from BP monitoring, MAP calculation in the first and second trimesters is significant since the MAP is a stronger predictor of preeclampsia than SBP, DBP, or a rise in BP. ${ }^{6} \mathrm{~A}$ combination of maternal demographic data, including medical and obstetric history, MAP, and a number of additional biophysical and biochemical indicators, are used to screen for PE during 11-13 weeks gestation and is highly effective in identifying pregnancies that will develop early PE. ${ }^{7-9}$ According to a metaanalysis, MAP of $90 \mathrm{mmHg}$ has a sensitivity of $62 \%$ (35 percent to 89 percent) and specificity of $82 \%$. (72 percent to 92 percent). ${ }^{10}$

Rationale of this study is to assess the accuracy of mean arterial pressure for diagnosis of 
preeclampsia in females presenting in second trimester. According to the literature, MAP could be a good alternative for predicting preeclampsia in early pregnancy. However, disputed results have been reported in the literature, as sensitivity and specificity varied widely across investigations. Furthermore, no local evidence exists in this regard. As a result, we performed this investigation to uncover local evidence. This will improve clinical abilities as well as local guidelines for prevention and care of such cases.

\section{MATERIAL \& METHODS}

This Cross-sectional study was conducted at, Department of Obstetrics \& Gynecology Unit III, Allied hospital, Faisalabad from October 2016 to September 2017 with 95\% confidence interval and absolute precision of $8 \%$. After approval from hospital Ethical committee (667/2016) total 386 patients were enrolled after obtaining informed consent. Booked females of age 1840 years, parity $<5$ presenting at gestational age $>16$ weeks (on LMP) for antenatal checkup were included in study. Patients with multiple gestation (on medical record and USG), females with chronic hypertension (BP $\geq 140 / 90 \mathrm{mmHg}$ ), chronic or gestational diabetes (BSR $>186 \mathrm{mg} /$ $\mathrm{dl})$, females having oligohydramnios ( $\mathrm{AFI}<5 \mathrm{~cm}$ ) or polyhydramnios (AFI>21cm) on USG, having abnormal placental implantation or placental abruption (on USG) were excluded from study. MAP calculated as DBP $+1 / 3($ SBP-DBP). MAP was considered raised and predictive of preeclampsia when MAP $\geq 90 \mathrm{mmHg}$ during 16-23weeks of gestation. On actual preeclampsia was considered when $B P \geq 140 / 90 \mathrm{mmHg}$ and proteinuria $\geq+1$ on dipstick method after 24th weeks of gestation on LMP.

Enrolled females were followed-up in OPD till delivery. During follow-up, blood pressure noted on each visit and urine sample was obtained in sterile container. Dipstick was dipped in container and results were obtained for assessment of proteinuria. If $B P \geq 140 / 90 \mathrm{mmHg}$ and proteinuria $\geq+1$, then preeclampsia was labeled. All this information was recorded on proforma.
Statistical Analysis was done on SPSS version 21. Quantitative variables like age and gestational age, SBP, DBP and MAP was calculated as mean and standard deviation. Categorical variable like parity, proteinuria and preeclampsia was calculated as frequency and percentage. Data was stratified for age, gestational age, and parity. Post-stratification, $2 \times 2$ tables was generated to calculate sensitivity, specificity, PPV, NPV and diagnostic accuracy of MAP.

\section{RESULTS}

We enrolled 386 cases with mean age of $28.6 \pm 6.9$ years. The youngest patient was 18 years old and 40 years was the maximum age. The mean gestational age was $18.4 \pm 1.7$ weeks with minimum of 16 weeks and maximum 21 weeks. Out of total patients, 206(53.4\%) patients were primigravida, $82(21.24 \%)$ patients with parity one, $46(11.9 \%)$ patients with parity two, 29(7.5\%) patients with parity three and 23(5.96\%) patients were with parity four. The MAP was $94.9 \pm 14.7$ $\mathrm{mmHg}$ with minimum value of $70 \mathrm{mmHg}$ and maximum $120 \mathrm{mmHg}$. (Table-I)

MAP was raised above $90 \mathrm{mmHg}$ in $238(61.66 \%)$ patients and it was below $90 \mathrm{mmHg}$ in 148(28.34\%) patients. The mean SBP was $146.37 \pm 21.05$ $\mathrm{mmHg}$ and the mean DBP of the patients was $91.82 \pm 11.88 \mathrm{mmHg}$. On follow-up, 239(61.9\%) patients developed preeclampsia with proteinuria $>+1$. The diagnostic accuracy of MAP in preeclampsia was found to be $91.45 \%$.

It was further evaluated that MAP in patients of younger age (<30years), with primiparity and with advancing pregnancy was more predictive of Preeclampsia later in pregnancy. Stratification was done according to age, parity and gestational age. MAP has higher sensitivity for the diagnosis of preeclampsia in age $<30$, primiparity and gestational age 18-21weeks. Diagnostic accuracy was also better in age $<30$ years and gestational age 18 to 21 weeks. The Sensitivity, specificity, Positive predictive value and negative predictive value of MAP for the prediction of preeclampsia in each stratified group is shown in table. (Table-II) 


\begin{tabular}{|l|c|}
\hline \multicolumn{1}{|c|}{ Characteristics } & $\mathbf{n = 8 1}$ \\
\hline Age (years) & $28.59 \pm 6.93$ \\
\hline Gestational Age (weeks) & $18.38 \pm 1.68$ \\
\hline MAP (mmHg) & $94.88 \pm 14.68$ \\
\hline SBP & $146.37 \pm 21.05$ \\
\hline DBP & $91.82 \pm 11.88$ \\
\hline Protienuria $(>+1)$ & $61.9 \%(239)$ \\
\hline Protienuria $(<+1)$ & $38.1 \%(147)$ \\
\hline MAP Preeclampsia (positive) & $61.66 \%(238)$ \\
\hline Preeclampsia (positive) & $61.9 \%(239)$ \\
\hline \multicolumn{2}{|c|}{ Table-I. Risk factors for metabolic syndrome with } \\
\multicolumn{2}{|c|}{ gender specification. } \\
\hline
\end{tabular}

\section{DISCUSSION}

In antenatal care, blood pressure monitoring is commonly used to diagnose hypertensive disorders during pregnancy. Because the findings of these studies are mixed, it's unclear if blood pressure monitoring should be used frequently as a predictive test or only to evaluate suspected hypertensive problems in pregnancy. Pre-eclampsia is accurately predicted by mean arterial pressure, while it is weakly predicted by SBP and DBP. ${ }^{11}$

In our study the sensitivity and diagnostic accuracy of MAP for diagnosing Preeclampsia was $92.89 \%$ and $91.45 \%$ respectively. A study by Jeltsje $S$ Cnossen et al ${ }^{12}$ found that in the first and second trimesters, mean arterial pressure is a stronger predictor of pre-eclampsia than a rise in blood pressure. A positive likelihood ratio of 3.5 (95 percent confidence interval 2.0 to 5.0) and a negative likelihood ratio of 0.46 were found for second trimester mean arterial pressure of 90 $\mathrm{mm} \mathrm{Hg}$ or greater (0.16 to 0.75 ). According to a meta-analysis, MAP of $90 \mathrm{mmHg}$ had a pooled sensitivity of $62 \%$ (35 percent to 89 percent) and a pooled specificity of $82 \%$. (72 percent to 92 percent). CA Walsh et al ${ }^{13}$ found comparable findings in low-risk women.

Ahmed Al-Amin et $\mathrm{al}^{14}$ found that screening for preterm preeclampsia in the second trimester using a combination of maternal history, mean arterial pressure, and mean uterine artery Doppler pulsatility index (FMF algorithm) was superior to screening using maternal variables alone. The detection rates for preterm preeclampsia were predicted to be 75 percent $(95$ percent $\mathrm{Cl} 34.9$ 96.8) and 87 percent (95 percent $\mathrm{Cl} 47.3-99.6$ ) by NICE guidelines and ACOG recommendations, respectively, whereas it was 100 percent for both the FMF algorithm with a 1:100 cut-off and the FMF algorithm with a 1:60 cut-off.

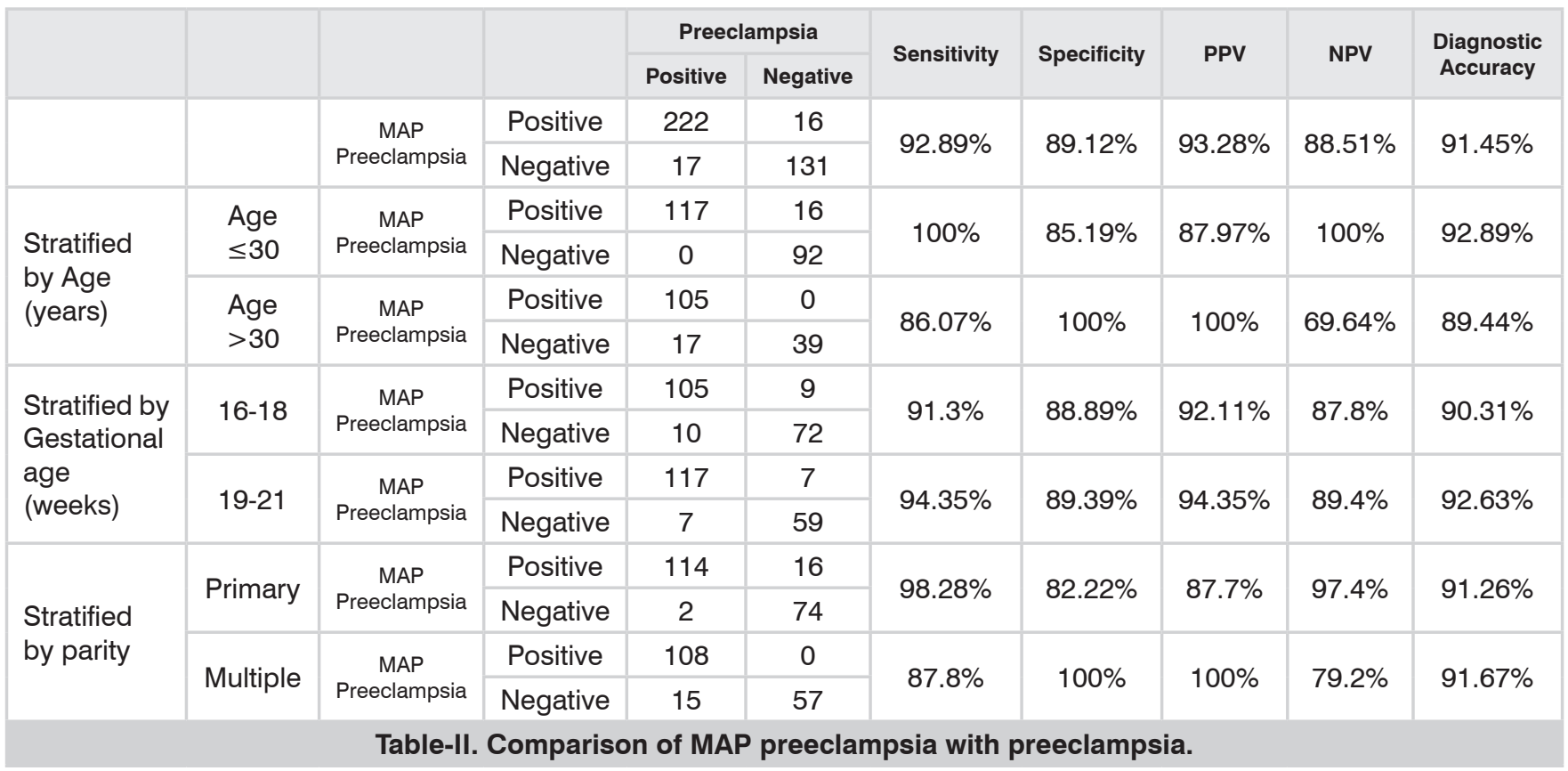


At 11-13 weeks gestation, a combination of maternal demographic variables, such as medical and obstetric history, MAP, and a range of additional biophysical and biochemical indicators is highly successful in predicting pregnancies that would develop early PE rather than intermediate or late $P E .^{7-9}$ Maternal history, mean arterial pressure (MAP), serum pregnancy-associated PPA, placental growth factor, and uterine artery pulsatile index were found to be particularly efficient in predicting early preeclampsia at 11 to 13 weeks of pregnancy. Previous Preeclampsia and MAP >95 mmHg were linked to an increased risk of superimposed $P E$ in essential chronic hypertensive women treated before pregnancy, according to Lecarpentier et al. ${ }^{15}$

According to Leona C. Poon and Kypros $\mathrm{H}$. Nicolaides ${ }^{16}$, screening for early onset PE using maternal risk factors, uterine artery Doppler, maternal serum pregnancy-associated plasma protein-A, placental growth factor, and mean arterial pressure detects about $95 \%$ of cases with a $10 \%$ false-positive rate.

\section{CONCLUSION}

The mean arterial pressure in second trimester is very effective and useful screening method for prediction of preeclampsia with high values of sensitivity, specificity and diagnostic accuracy.

\section{Copyright $(13$ Sep, 2021.}

\section{REFERENCES}

1. Macdonald-Wallis C, Silverwood RJ, De Stavola BL, Inskip H, Cooper C, Godfrey KM, et al. Antenatal blood pressure for prediction of pre-eclampsia, preterm birth, and small for gestational age babies: Development and validation in two general population cohorts. Br Med J 2015; 351:h5948.

2. Poon LC, Kametas NA, Pandeva I, Valencia C, Nicolaides $\mathrm{KH}$. Mean arterial pressure at $11+0$ to $13+6$ weeks in the prediction of preeclampsia. Hypertension 2008; 51(4):1027-33.

3. Shamsi U, Saleem S, Nishter N. Epidemiology and risk factors of preeclampsia; An overview of observational studies. Al Ameen J Med Sci 2013; 6(4):292-300.
4. Mustafa R, Ahmed S, Gupta A, Venuto RC. A comprehensive review of hypertension in pregnancy. Journal of pregnancy. 2012 Oct;2012.

5. Poon LC, Nicolaides KH. Early prediction of preeclampsia. Obstet Gynecol Int 2014; 2014:Article ID 297397.

6. Vollebregt KC. Hemodynamics and maternal characteristics prior to hypertensive disorders of pregnancy. Amsterdam: University of Amsterdam; 2011.

7. Akolekar R, Syngelaki A, Sarquis R, Zvanca M, Nicolaides $\mathrm{KH}$. Prediction of early, intermediate and late pre $\square$ eclampsia from maternal factors, biophysical and biochemical markers at 11-13 weeks. Prenat Diag 2011; 31(1):66-74.

8. Poon LC, Kametas NA, Valencia C, Chelemen T, Nicolaides $\mathrm{KH}$. Hypertensive disorders in pregnancy: screening by systolic diastolic and mean arterial pressure at 11-13 weeks. Hypertens Pregnan 2011; 30(1):93-107.

9. Akolekar R, Syngelaki A, Poon L, Wright D, Nicolaides $\mathrm{KH}$. Competing risks model in early screening for preeclampsia by biophysical and biochemical markers. Fet Diag Therap 2012; 33(1):8-15.

10. Cnossen JS, Vollebregt KC, de Vrieze N, ter Riet G, Mol $B W$, Franx $A$, et al. Accuracy of mean arterial pressure and blood pressure measurements in predicting preeclampsia: Systematic review and meta-analysis. $\mathrm{Br}$ Med J 2008; 336(7653):1117-20.

11. Sibai B, Dekker G, Kupferminc M. Pre-eclampsia. The Lancet 2005; 365(9461):785-99.

12. Cnossen JS, Vollebregt KC, de Vrieze N, ter Riet G, Mol $B W$, Franx A, et al. Accuracy of mean arterial pressure and blood pressure measurements in predicting preeclampsia: Systematic review and meta-analysis. Bmj 2008; 336(7653):1117-20.

13. Walsh CA, Baxi LV. Mean arterial pressure and prediction of pre-eclampsia. BMJ: British Medical Journal 2008; 336(7653):1079.

14. Al $\square$ Amin A, Rolnik DL, Black C, White A, Stolarek C, Brennecke S, da Silva Costa F. Accuracy of second trimester prediction of preterm preeclampsia by three different screening algorithms. Australian and New Zealand Journal of Obstetrics and Gynaecology. 2018 Apr; 58(2):192-6. 
15. Lecarpentier E, Tsatsaris V, Goffinet F, Cabrol D, Sibai B, Haddad B. Risk factors of superimposed preeclampsia in women with essential chronic hypertension treated before pregnancy. PLOS One 2013; 8(5):e62140.
16. Poon LC, Nicolaides $\mathrm{KH}$. Early prediction of preeclampsia. Obstetrics and gynecology international. 2014 Jul 17;2014.

\section{AUTHORSHIP AND CONTRIBUTION DECLARATION}

\begin{tabular}{|c|l|l|}
\hline No. & \multicolumn{1}{|c|}{ Author(s) Full Name } & \multicolumn{1}{|c|}{ Contribution to the paper } \\
\hline 1 & Sidra Mushtaq & 1st Author \\
2 & Naeem Hameed & 2nd Author \\
3 & Rabika Bint Khamis Butt & 3rd Author \\
4 & Shahid Abbas & 4th Author \\
5 & Ali Sajjad & 5th Author \\
\hline
\end{tabular}

